\title{
FOOD CONSUMPTION, LIFESTYLE PATTERNS AND BODY MASS INDEX OF A GROUP OF WHITE SOUTH AFRICAN STUDENTS
}

\author{
Annemarie T. Viljoen*, Esther van der Spuy and Gerrie E. du Rand
}

Department of Consumer Science, University of Pretoria, Pretoria, South Africa

\section{* Correspondence}

Annemarie T. Viljoen, Department Consumer Science, University of Pretoria, Private Bag x20, Hatfield, Pretoria 0028 ZA, South Africa.

Email: annemarie.viljoen@up.ac.za

\begin{abstract}
There is worldwide concern that higher education students are increasingly engaging in unhealthy eating and lifestyle practices. A total of 488 white students participated in a study aimed at investigating the current food consumption and related lifestyle patterns of students at a South African residential university. The respondents' self-reported weight and height was used to calculate their body mass index (BMI). Closed and open-ended questions measured aspects of the respondents' usual eating patterns and lifestyles.
\end{abstract}

The meal patterns and composition confirmed Western-orientated food practices, as the majority consumed three meals a day, with in-between meal snacking, and a different meal pattern over weekends. Respondents' food intake was further characterised by a low intake of fruit, vegetables and dairy products and frequent consumption of foods high in fat, sugar and sodium. Although the majority $(66.8 \%)$ of the study group were classified as normal weight according to their BMI, when comparing males and females, more males than females were overweight and obese. Only $54 \%$ of the males had a normal weight compared to $82 \%$ of the females. There was, however, no statistically significant difference $(p=0.149)$ between how males and females in the different BMI groups felt about their weight.

The study also explored the relationships between the respondents' BMI, gender, food consumption patterns and type of residence. The features of the food consumption patterns were depicted according to whether breakfast was eaten or not; snacking activity between meals; the consumption of ready-prepared convenience meals, fast foods; home-cooked meals; and eating out. There were no statistical significant differences between the BMI categories of males and females regarding their habit to eat breakfast or not; and to snack between meals either during the morning, in the afternoon or after supper. Similarly, no 
statistical significant differences were noted when relating the BMI categories of the gender groups to the frequency of consumption of ready-prepared, convenience type meals, fast foods and home-cooked meals. However, a statistical significant difference ( $p$-value 0.006) was found between BMI categories per gender and general frequency of eating out. No statistical differences was noted between BMI categories, gender and place of residence irrespective of the type, whether the student lived with parents, independently in a flat or apartment, or a house with friends or a room, or in a university residence.

\section{KEYWORDS}

Food consumption patterns, lifestyle, body mass index, students, food choice

\section{INTRODUCTION}

The increasing incidence of overweight and obesity among young adults due to the nature of their eating patterns is a public health concern globally (Laska et al., 2009a; Larson et al., 2009; Deliens et al., 2013; Kelly et al., 2013 Peltzer et al., 2014). Young adulthood, typically defined as between the ages of 18 and 25 years, is the transition phase from adolescence to adulthood. It is identified as a period when lifestyle changes in particular take place, especially the adoption of new eating patterns. It is the time when a young person usually leaves home to study or find employment or even does both. For many, it is characterised by becoming independent, enjoying and exploring, the freedom of making their own decisions about their lifestyle especially their food choices (Sharma et al., 2010; Chourdakis et al., 2011; Riddell et al., 2011; De Backer, 2013; Kelly et al., 2013). This life stage therefore has the propensity to be a high risk life stage for the development of obesity (Laska et al., 2009a; El Ansari et al., 2011; Larson et al., 2011; Riddell et al., 2011; Deliens et al., 2013; Peltzer et al., 2014). At the individual level, a lifestyle is grounded in habits and beliefs (Jensen, 2007; Von Normann, 2009). By implication, lifestyle can thus be regarded as habits stemming from rules and standards that influence the orientation of an individual's consumption behaviour.

An investigation into the food consumption and lifestyle patterns of university students is feasible considering their stage of life. Many young adults experience this phase of tertiary education and preparation for a future career as marked by changes in lifestyle and stress (EI Ansari et al., 2011; Schnettler et al., 2015). These often include having to take responsibility for their own food choices and meal patterns (Cluskey \& Grobe, 2009; Sharma et al., 2010; Chourdakis et al., 2011; Riddell et al., 2011; De Backer, 2013; Kelly et al., 2013). This particular life stage is also viewed as critical in the development of eating habits, as these are likely to follow on into adulthood with implications for their own long-term health and wellbeing, and that of their future families (Cluskey \& Grobe, 2009; Laska et al., 2009b; Sharma 
et al., 2010; Casini et al., 2013; Hartman et al., 2013; Schnettler et al., 2015). This study therefore investigated a group of students' food consumption patterns that included apart from the number and types of meals and snacking in-between meals, lifestyle patterns associated with food consumption such as the frequency of consumption of fast foods, home-cooked meals, ready-prepared / convenience meals and type of residence.

\section{LITERATURE REVIEW}

Exercising freedom to make decisions about lifestyle and food choices is likely to mean the adoption of new eating behaviours (Sharma et al., 2010; Chourdakis et al., 2011; Riddell et al., 2011; Janse van Rensburg et al., 2013). There are studies that report that tertiary education students often engage in unhealthy lifestyle practices like irregular eating times; consuming poor quality diets; being less physically active; starting to smoke; and consuming alcoholic beverages and/or drugs (Papadaki et al., 2007; Kourlaba et al., 2009; Sharma et al., 2010; Chourdakis et al., 2011; El Ansari et al., 2011; Li et al., 2012; Hartman et al., 2013; Janse van Rensburg et al., 2013; Peltzer et al., 2014). These practices are attributed to, amongst other issues, the adjustment to student life and a hectic social and study programme that contribute to perceived and real time constraints, and a limited budget. Food choices often have to be guided by budgetary and time constraints. Hence they inevitably are the affordable, energy dense food items that the student can consume when on the go. Although these provide the needed energy and satiety, they often have a low nutrient density. Such food choices, together with a decline in activity levels, are often associated with a lifestyle that results in overweight and ultimately obesity.

\section{Concerns and consequences}

The link between developing non-communicable diseases (NCDs) as a result of overweight and obesity is well-documented (Low et al., 2009 Chourdakis et al., 2010; Abrahams et al., 2011; Van den Berg et al., 2013; Peltzer et al., 2014; Steyn and Michiza, 2014). Further concern is expressed about the increasing number of adults diagnosed with NCDs at an even younger age than previously (Low et al., 2009; Chourdakis et al., 2010; Riddell et al., 2011; Steyn and Mchiza, 2014; WHO, 2015). This trend is not only observed in Western developed countries, but is also on the increase in developing and many sub-Saharan countries (Tibazwara et al., 2009; Popkin et al., 2012; Vasileska and Rechkoska, 2012; Steyn and Mchiza, 2014). Also noted is that more young adults are reported as becoming prone to being overweight and obese, and are at risk of developing NCDs in later life (Larson et al., 2008; Gordon-Larsen et al., 2004). The pandemic of overweight and obesity is also on the rise in South Africa (Rossouw et al., 2012; Shisana et al., 2014; Steyn \& Mchiza, 2014; Van Niekerk 
et al., 2014; Sartorius et al., 2015). It is known that lifestyles, together with food consumption patterns and composition, have changed over the past decades (Beasley et al., 2004; Low et al., 2009; Chourdakis et al., 2010; Popkin et al., 2012; Abrahams et al., 2011; Casini et al., 2013; Steyn and Mchiza, 2014). A consequence of this trend has not only led to changing eating habits but also to a simultaneous increase in the prevalence of overweight and obese people with NCDs. It can thus be assumed that the increase observed in recent overweight and obesity statistics reflects underlying changing food habits and lifestyles.

\section{Contributing factors}

A complex matrix of factors that are subject to change over time influence food consumption patterns (Sobal et al., 2006; Brunt and Rhee, 2008; Casini et al., 2013; Sobal an Hanson, 2014). In recent times, the structure of food consumption patterns has changed significantly globally as it has been driven by modernisation, urbanisation, globalisation, technological advancements and social transformations (Popkin et al., 2012; Igumbor et al., 2012; Stucker and Nestle, 2012; Casini et al., 2013). The manner in which eating patterns have evolved and changed in terms both of quantity and quality of food consumed characterises the nutrition transition (Vasileska \& Rechkoska, 2012; Casini et al., 2013). This situation has arisen as more processed foods have become available at affordable prices leading ultimately to an increased intake of fat, protein and sugars (Popkin et al., 2012; Igumbor et al., 2012; Vasileska and Rechkoska, 2012; Ronquest-Ross et al., 2015; Scrinis, 2015). A decline in food containing complex carbohydrates and dietary fibre together with a lower intake of legumes, fruit and vegetables and calcium rich foods complements this trend (Popkin et al., 2012; Vasileska and Rechkoska, 2012). A scarcity of time, real or perceived, drives the development of such changes in food consumption patterns. This can, in turn, be attributed to social change. Induced by modernisation, technological advancement and urbanisation, change has not only led to a faster pace of life pace but, unfortunately, also to physical inactivity or a sedentary lifestyle (Popkin et al., 2012).

\section{Students' food consumption patterns}

There is worldwide concern that higher education students are increasingly engaging in unhealthy eating and lifestyle patterns. Several recent studies in the United States of America and European countries have investigated the food choice and consumption patterns of young adults in relation to body mass index (BMI) and various lifestyle factors to gain insight into their food consumption behaviour (Beasley et al., 2004; Bryant and Dundes, 2008; Larson et al., 2009; Sharma et al., 2010; Brittin and Obeidat, 2011; Chourdakis et al., 2011; Riddell et al., 2011; Casini et al., 2013; Deliens et al., 2013; Hartmann et al., 2013; Poinhos et al., 2013). The intention was to develop intervention strategies to enhance healthy eating through being 
aware of this group's living arrangements, fast food consumption, time constraints and their use of ready-prepared and other convenience foods. Studies on the food consumption patterns of South Africans, however, remain scarce (Van Heerden and Schönfeldt, 2011).

Lately a number of South African researchers have dealt with several aspects relating to the food adolescents and young adults tend to consume (Van Zyl et al., 2010; Kroone and Alant, 2012; Van den Berg et al., 2012; Van den Berg et al., 2013; Audian et al., 2014; Sedibe et al., 2014; Gresse et al., 2015). The connection between food intake and lifestyle behaviour of South African student groups in specific regions of the country is another topic of interest (Gresse et al., 2015; Van den Berg et al., 2013; Janse van Rensburg et al., 2013; Van den Berg et al.,2012). Another study specifically compared the eating and drinking behaviour of Health Science students, who are supposed to be more knowledgeable, with those of other students at the Nelson Mandela Metropolitan University in Port Elizabeth (Gresse et al., 2015). In two separate studies, Van den Berg and co-workers reported on body weight, eating practices and the nutritional knowledge of a predominantly black group of nursing students in the Eastern Cape in 2012; and the nutritional status of undergraduate health care students at the University of the Free State in 2013. The study of Janse van Rensburg et al. (2013) with university students from three universities in Gauteng, South Africa, focused on gender differences in students' health and lifestyles habits, with limited questions on food practices as part of lifestyle habits. The study by Van Zyl et al. (2010) into the fast food consumption patterns of young adults in Johannesburg according to socio-economic grouping considering factors that influence fast food intake. However, it did not report on other aspects of food consumption.

To implement successful interventions to improve the food consumption practices of young South African adults that could curb the rising pandemic of overweight and obesity first requires a thorough understanding of the food choices and food consumption patterns of young adults, in this transitional life stage. However, a paucity of data on the food intake of young adults from the country's various population groups of South Africa persists. Studies on white rural and urban populations specifically have decreased in the past 30 years (Van Heerden and Schönfeldt, 2011; Mchiza et al., 2015). The first South African Health and Nutrition Examination Survey, 2012 (SANHANES-1) did investigate certain aspects of the health and nutritional status of South Africans of all age groups concerning the prevalence of NCDs and various associated risk factors. Although dietary intake and behaviour were measured, it did not report on the food choice and consumption patterns of the study group (Shisana et al., 2014). Thus, except for the study by Van den Berg et al., (2013), no recent study on the food intake of the young urban white adult population could be found. The aim of 
this present study focused on the food consumption and related lifestyle patterns of a group of white students at a residential South African university who voluntarily gave information about their weight and height. This afforded an opportunity to explore the relationship between students' BMI categories and their selected food consumption and lifestyle patterns that relate to food such as the frequency of consumption of fast foods, home-cooked meals, readyprepared / convenience meals, eating out and type of residence. How respondents' felt about their current weight was also determined; as recent South African studies revealed that many young adults engage in unhealthy weight control practices to meet their perceived ideal body image (Gitau et al., 2014). In addition the SANHANES-1 study (Shisana et al., 2014:200) pointed out that South Africans do not seem to understand what is meant by 'normal weight' as only a small minority of the participants were able to identify the normal weight silhouette as ideal weight to strive for.

\section{METHODOLOGY}

This study formed part of a larger study on the food practices of students on the main campus of a residential university in Pretoria, South Africa. The Faculty's Ethics Committee granted ethical approval and students who responded were assured of anonymity and confidentiality. Similar to other studies (Riddell et al., 2011; Poinhos et al., 2013), convenience sampling was used and students from all racial groups (black African, coloured, Indian and white) were approached on campus and invited to participate in the study. A total of 488 white students, gave their informed consent to participate in the study and rendered self-reported information on their own weight and height, needed to calculate their BMI,. Although self-reported height and weight information might have included reporting bias, it is a method that is used frequently (Sobal and Hanson, 2011; Worsley et al., 2012; Poinhos et al., 2013; Sobal and Hanson, 2014). Height and weight were used to construct a continuous measure of BMl as $\mathrm{kg} / \mathrm{m}^{2}$. The BMl was used to create dichotomous indicators of underweight $(\mathrm{BMI}<18.5)$, normal weight (BMI 18.5 - <25), overweight (BMI $\geq 25)$ and obesity (BMI $\geq 30)$ (WHO 2015).

\section{Data collection}

A paper-based survey questionnaire applied and validated in previous research on young adults in the South African context was used to collect data on the food choice and other foodrelated behaviours of the study group (Fisher et al., 2016). Questionnaires were distributed by using the drop-off, collect later method to allow respondents to complete the questionnaire in their own time without any direct assistance or intervention from the researcher. The

questionnaire consisted of three sections, namely a section on the socio-demographic information, followed by a section on the usual eating patterns and lifestyle with the third 
section containing the food frequency questionnaire (FFQ). The selected socio-demographic variables for the questionnaire concerned age, gender, racial group, type of residence, the respondent's own height and weight and their satisfaction with their current weight by indicating whether they were satisfied with their own weight or needed to gain or lose weight. Closed and open-ended questions measured aspects of each respondent's usual eating patterns and lifestyles. Respondents were asked for information, with an accompanying reason, about the number of meals eaten each day and whether they had breakfast or not; the frequency of consumption of home-cooked meals, fast foods, ready-prepared, convenience type of meals; and eating out. Respondents were required to report directly on the questionnaire, what they usually (3-4 times a week) ate as meals and snacks at specific times during the day on weekdays. They also had to indicate if it was a regular practice or not. In addition, a closed question referred to their weekend eating patterns and enquired whether these tended to differ from weekday routines, and if so, to describe how. Respondents were only required to describe what they consumed as the questionnaire did not ask about quantities of food eaten like portion sizes or number consumed. The non-quantitative food frequency questionnaire (the third section of the survey questionnaire) yielded additional food consumption information and served as a crosscheck for the food intake data obtained. In the food frequency questionnaire 85 food items were grouped into twelve sub-groups. The subgroups were; bread and bread-like products, spreads or accompaniments to bread, cereals, vegetables, fruit, meat and meat products, fish and seafood, other protein foods, milk and dairy products, sweets and confectionary, beverages and snack foods. Respondents had to indicate how often they consumed each food item according the following scale; daily, 3-4 times per week, once a week, 1-3 times per month and never. The non-quantitative food frequency questionnaire served as check and triangulation of the reported usual eating patterns and provided a meaningful overview of the food consumption patterns of the study group. A question on the frequency of participation in sport or physical activity was part of the section on lifestyle measures.

\section{Data analysis}

The statistical analysis came from IBMC SPSSC version 23 software and a normality test for BMI, the dependent variable, from a one-sample Kolmogrov-Smirnov test. The sample mean is asymptotically, approximately normally, distributed and parametric tests were used as the sample was large. All p-values were two-sided and differences were considered significant in cases where the $p$-value was less than 0.05 . For comparison of categorical data, the chisquare $\left(\mathrm{X}^{2}\right)$ or Fisher's exact test for $2 \times 2$ data tables was used. 
TABLE 1 Characteristics of respondents $(N=488)$

\begin{tabular}{|c|c|c|}
\hline & $n$ & $\%$ \\
\hline \multicolumn{3}{|l|}{ Age } \\
\hline 18 & 25 & 5.20 \\
\hline 19 & 129 & 26.82 \\
\hline 20 & 86 & 17.88 \\
\hline 21 & 97 & 20.17 \\
\hline 22 & 88 & 18.30 \\
\hline 23 & 37 & 7.69 \\
\hline 24 and older & 19 & 3.95 \\
\hline \multicolumn{3}{|l|}{ Gender } \\
\hline Male & 268 & 55.37 \\
\hline Female & 216 & 44.63 \\
\hline \multicolumn{3}{|l|}{ Home language } \\
\hline Afrikaans & 340 & 73.43 \\
\hline English & 116 & 25.05 \\
\hline Other & 7 & 1.51 \\
\hline \multicolumn{3}{|l|}{ Type of residence } \\
\hline Live with parents & 133 & 27.48 \\
\hline Live independently & 148 & 30.58 \\
\hline Residence & 200 & 41.32 \\
\hline \multicolumn{3}{|c|}{$\begin{array}{l}\text { Participation frequency in sport or } \\
\text { physical activity }\end{array}$} \\
\hline Daily & 113 & 23.40 \\
\hline 3-4 times a week & 189 & 39.13 \\
\hline Once a week & 101 & 20.91 \\
\hline 2-3 times a month & 49 & 10.14 \\
\hline Never & 31 & 6.42 \\
\hline \multicolumn{3}{|l|}{ Missing values $=5$} \\
\hline \multicolumn{3}{|l|}{ Body mass index } \\
\hline Underweight & 31 & 6.40 \\
\hline Normal weight & 326 & 66.80 \\
\hline Overweight & 107 & 21.92 \\
\hline Obese & 22 & 4.50 \\
\hline
\end{tabular}




\section{RESULTS}

\section{Characteristics of the sample}

Table 1 provides information on the demographic profile, the place of residence, BMI categories and participation frequency in sport or physical activity of the respondents. The majority fell within the age group of 19-22 years old, the typical age range of tertiary students in South Africa. Although females were well-represented in the sample (44.63\%), male respondents $(55.37 \%)$ were slightly more dominant. This could probably be because males are not as sensitive as females about self-reporting their own weight. The home language of the majority (73.43\%) was Afrikaans. Many stayed in the university residence $(41.32 \%)$ whereas $30.58 \%$ lived independently in a flat, a room or shared a house with friends and $27.48 \%$ still lived with their parents. Some respondents frequently participated in sport or engaged in physical activity, with $23.40 \%$ doing so daily and $39.13 \%$ who did so $3-4$ times a week. However, just over a third of the study group could be described as being inactive as they participated in sport or physical activity only once a week, 2-3 times a month or never.

Although nearly two-thirds (66.8\%) of the study group, a sizeable proportion, were classified as having a normal weight according to their BMI (Table 1). When comparing males and females, more males than females were overweight and obese. Only $54 \%$ of the males had a normal weight compared to $82 \%$ of the females (Table 2). Thirty-five per cent of males were overweight and $7 \%$ obese in comparison to $6 \%$ of the females who were overweight and $1.4 \%$ who were obese. Only $3 \%$ males compared to $10 \%$ of the females were underweight. Oneway analysis of variance (Anova) indicated a statistically significant difference between the mean BMI of male and female students $(p=0.00)$. Table 3 presents the respondents' feelings about their current weight, measured as either satisfied or need to lose or gain weight. Although the majority who felt satisfied had a normal weight, more normal weight females (84.5\%) felt they had to lose weight in comparison to the $18.2 \%$ normal weight males who felt they had to lose weight. For those who felt they needed to gain weight the majority were males $(72.1 \%)$ of normal weight. There were, however, no statistically significant differences ( $p=0.149$ ) between how males and females in the different BMI groups felt about their weight.

\section{Meal patterns}

Slightly more than half of the respondents $(58.8 \%)$ reported eating three meals a day with inbetween meal snacking. About two-thirds (65.98\%) consumed something small mid-mornings and just more than half did so mid-afternoons (53.07\%) and after supper (50.20\%). The majority (81.60\%) enjoyed breakfast and gave positive reasons for doing so. These included statements such as that it is essential to eat breakfast (36.57\%); or they regarded it as the 
TAB L E 2 BMl categories of the study group $(N=484)$

\begin{tabular}{|c|c|c|c|c|c|c|c|c|}
\hline & \multicolumn{2}{|c|}{ Males $(n=268)$} & \multirow[b]{2}{*}{ Mean } & \multirow[b]{2}{*}{ SD } & \multicolumn{2}{|c|}{$\begin{array}{l}\text { Females } \\
(n=216)\end{array}$} & \multirow[b]{2}{*}{ Mean } & \multirow[b]{2}{*}{ SD } \\
\hline & $n \%$ & & & & $n \%$ & & & \\
\hline Underweight & 9 & 3.4 & 17.5 & 1.02 & 22 & 10.2 & 17.7 & 0.78 \\
\hline Normal weight & 144 & 54.1 & 22.5 & 1.47 & 178 & 82.4 & 21.4 & 1.60 \\
\hline Overweight & 94 & 35.3 & 27.0 & 1.40 & 13 & 6.0 & 26.3 & 1.24 \\
\hline Obese & 19 & 7.1 & 33.6 & 5.72 & 3 & 1.4 & 35.7 & 5.97 \\
\hline
\end{tabular}

Note. One-way ANOVA $p=0.00$.

$\mathrm{BMI}=$ weight $(\mathrm{kg}) /$ height $\left(\mathrm{m}^{2}\right) ; \quad$ Underweight-BMI < 18.5; Normal weight-BMI 18.5-<25; Overweight $-\mathrm{BMI}=25$; Obese $-\mathrm{BMI}=30$ (WHO, 2015). 
TAB LE 3 Relationship BMI, gender and feelings about current weight

\begin{tabular}{|c|c|c|c|c|c|c|c|c|c|c|c|}
\hline & & & \multicolumn{4}{|l|}{ Males } & \multicolumn{4}{|l|}{ Females } & \multirow[b]{2}{*}{ Sign diff } \\
\hline & & & Underweight & Normal weight & Overweight & Obese & Underweight & Normal weight & Overweight & Obese & \\
\hline \multirow{6}{*}{$\begin{array}{l}\text { Feelings about } \\
\text { current weight }\end{array}$} & \multirow[t]{2}{*}{ Satisfied } & Count & 4 & 99 & 44 & 8 & 16 & 79 & 1 & 0 & 0.149 \\
\hline & & $\begin{array}{l}\% \text { within BMI } \\
\text { categories }\end{array}$ & 2.6 & 63.9 & 28.4 & 5.2 & 16.7 & 82.3 & 1.0 & 0.0 & \\
\hline & \multirow{2}{*}{$\begin{array}{l}\text { Need to } \\
\text { lose } \\
\text { weight }\end{array}$} & Count & 0 & 12 & 43 & 10 & 2 & 93 & 12 & 3 & \\
\hline & & $\begin{array}{l}\% \text { within BMI } \\
\text { categories }\end{array}$ & 0.0 & 18.5 & 66.2 & 15.4 & 1.8 & 84.5 & 10.9 & 2.7 & \\
\hline & \multirow{2}{*}{$\begin{array}{l}\text { Need to } \\
\text { gain } \\
\text { weight }\end{array}$} & Count & 5 & 31 & 6 & 1 & 3 & 2 & 0 & 0 & \\
\hline & & $\begin{array}{l}\% \text { within BMI } \\
\text { categories }\end{array}$ & 11.6 & 72.1 & 14.0 & 2.3 & 60.0 & 40.0 & 0.0 & 0.0 & \\
\hline
\end{tabular}


most important meal of the day; or had the view that that it provided energy or strength for the day. These were followed by those who gave reasons like feeling hungry and/or they need food $(31.71 \%)$. Those who did not eat breakfast (19\%) gave reasons related to time constraints: they did not have time to eat or prepare breakfast; or they slept too late; or were either not hungry; or cannot eat early in the morning. Weekend meal patterns differed from those on weekdays, although only slightly - 58.2\% Saturdays and $55.9 \%$ on Sundays. Reasons given in an open-ended question for the differences mainly related to the type and quantities of food consumed. Thirty-three per cent of the responses indicated that more snack and take-away foods were consumed on Saturdays because of having a braai (barbeque) (11.26\%), a bigger breakfast (9.89\%) or simply eating more (7.97\%). A small number $(6.87 \%)$ indicated that more home-cooked food was eaten. The differences for Sundays were due to a home-cooked Sunday midday meal being enjoyed by $32.92 \%$; while $13.85 \%$ revealed that more take-away foods were bought; or braaivleis (barbeque) fare $(5.23 \%)$ was enjoyed; and some eat less (8.31\%) and some more (6.15\%).

\section{Meal composition}

Respondents reported what they usually eat or drink at specific times on weekdays (3-4 times a week) in an open-ended question. These times were grouped as breakfast (between $6 \mathrm{~h} 00$ and 9h00), mid-morning (between 9h00 and 12h00), Lunch (between $12 \mathrm{h00}$ and 15h00), midafternoon (between 15h00 and 17h00) and supper (between 17h00 and 20h00) and after supper (after 20h00). Figure 1 portrays the $2 \%$ or more responses for food and beverage items reported as part of the meal and snack composition. Breakfast cereals (25.91\%), and/or bread (15.5\%) was mainly consumed for breakfast although eggs (13.44\%), bacon (7.38\%) and dairy products such as milk (7.51\%) and yoghurt (5.33\%) were also on the menu. Fewer than $5 \%$ of the reported responses, revealed that coffee (4.84\%), soft cooked porridge (3.51\%), fruit $(2.66 \%)$ or fruit juice $(2.78 \%)$ and tea $(2.42 \%)$ were enjoyed at this meal. For lunch, about a quarter of the responses (26.7\%) showed that sandwiches or some form of bread were a common choice thus this midday meal can be described as bread-based. This is followed by chicken $(8.03 \%)$, meat $(7.01 \%)$, French fries (5.32\%), and pies (5.2\%). Vegetables $(7.47 \%)$ and fruit $(6.33 \%)$ were included as part of lunch. For supper, the main meal of the day, $19.5 \%$ indicated meat and $13.3 \%$ chicken as protein sources, followed by $20.23 \%$ who had vegetables, $12.37 \%$ mentioning potatoes, $6.5 \%$ pasta and $5.15 \%$ salads as important items.

The majority of the students (65\%) enjoyed a mid-morning snack that comprised fruit for nearly a quarter of the sample (24.1\%); $14.86 \%$ snacked on potato crisps; and a noticeable number (11.49\%) consumed sandwiches or bread. A smaller number nearly $4 \%$ of all the responses had snack items such as biscuits or cookies $(4.28 \%)$, muffins $(3.83 \%)$, chocolates $(4.73 \%)$ 


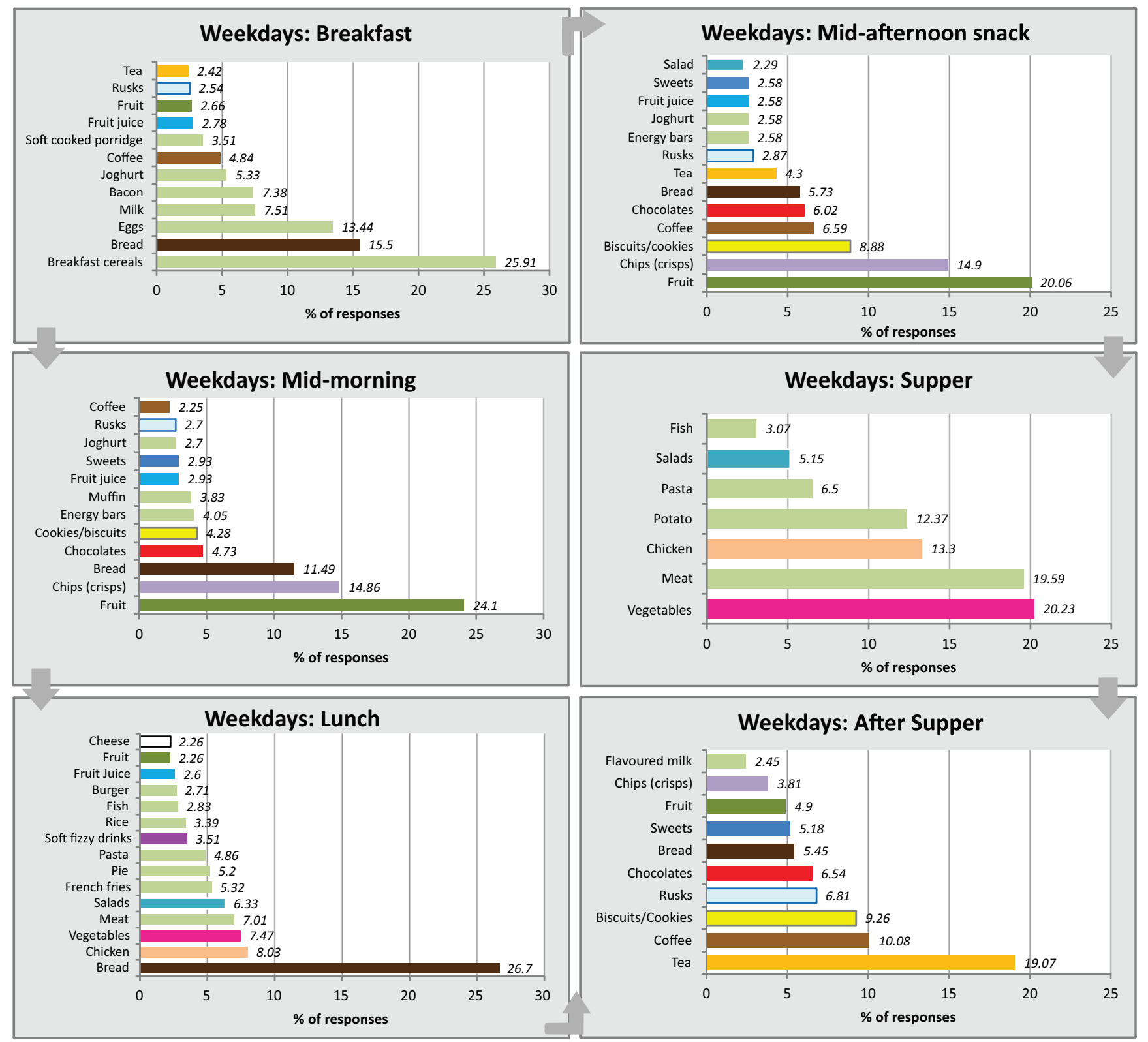

FIGURE 1 Food usually consumed (3-4 times a week) 
TAB LE 4 Frequency of consumption of vegetables, fruit, dairy products, and snack foods

\begin{tabular}{|c|c|c|c|c|c|c|c|c|c|c|}
\hline \multirow[b]{2}{*}{ Food group } & \multicolumn{2}{|c|}{ Daily } & \multicolumn{2}{|c|}{ 3-4 times a week } & \multicolumn{2}{|l|}{ Once a week } & \multicolumn{2}{|c|}{ 1-3 times a month } & \multicolumn{2}{|l|}{ Never } \\
\hline & $n$ & $\%$ & $n$ & $\%$ & $n$ & $\%$ & $n$ & $\%$ & $n$ & $\%$ \\
\hline \multicolumn{11}{|l|}{ Vegetables } \\
\hline $\begin{array}{l}\text { Green vegetables (broccoli, green beans, cabbage, } \\
\text { peas, spinach) }\end{array}$ & 118 & 24.58 & 233 & 48.51 & 61 & 12.71 & 35 & 7.29 & 33 & 6.88 \\
\hline Yellow vegetables (butternut, carrots, pumpkin) & 87 & 18.13 & 225 & 46.8 & 92 & 19.17 & 48 & 10.0 & 28 & 5.83 \\
\hline $\begin{array}{l}\text { Other vegetables (potato, cauliflower, mushroom, } \\
\text { onions, sweet potato, mealies) }\end{array}$ & 104 & 21.67 & 274 & 57.08 & 72 & 15.0 & 20 & 4.17 & 10 & 2.08 \\
\hline $\begin{array}{l}\text { Salads (beetroot, lettuce, cucumber, tomatoes, sweet } \\
\text { pepper) }\end{array}$ & 103 & 21.55 & 237 & 49.58 & 67 & 14.02 & 41 & 8.58 & 30 & 6.28 \\
\hline \multicolumn{11}{|l|}{ Fruit } \\
\hline Citrus fruit (oranges, naartjie, lemons) & 55 & 11.48 & 164 & 34.24 & 112 & 23.38 & 103 & 21.5 & 45 & 9.39 \\
\hline Vit A rich fruit (yellow peaches, mangoes, paw paw) & 23 & 4.82 & 107 & 22.43 & 107 & 22.43 & 133 & 27.88 & 107 & 22.43 \\
\hline Other fruit (grapes, bananas, apples, pears) & 84 & 17.50 & 176 & 36.67 & 109 & 22.71 & 76 & 15.83 & 35 & 7.29 \\
\hline \multicolumn{11}{|l|}{ Dairy products } \\
\hline Milk & 284 & 59.66 & 113 & 23.70 & 30 & 6.30 & 24 & 5.04 & 25 & 5.25 \\
\hline Yoghurt & 76 & 16.0 & 136 & 28.63 & 96 & 20.21 & 88 & 18.53 & 79 & 16.63 \\
\hline Cheese & 109 & 23.14 & 197 & 41.83 & 80 & 16.99 & 34 & 7.22 & 51 & 10.83 \\
\hline \multicolumn{11}{|l|}{ Snack foods } \\
\hline Sweets & 32 & 6.85 & 108 & 23.13 & 117 & 25.06 & 106 & 22.7 & 104 & 22.27 \\
\hline Chocolates & 34 & 7.16 & 124 & 26.11 & 118 & 24.84 & 117 & 24.63 & 82 & 17.26 \\
\hline Chips (crisps) & 18 & 3.81 & 138 & 29.18 & 145 & 30.66 & 111 & 23.47 & 61 & 12.9 \\
\hline Sugar-sweetened beverages & 70 & 14.83 & 148 & 31.36 & 70 & 14.83 & 73 & 15.47 & 111 & 23.52 \\
\hline Fruit juice & 98 & 20.59 & 189 & 39.71 & 100 & 21.01 & 43 & 9.03 & 46 & 9.66 \\
\hline Biscuits/cookies & 27 & 5.71 & 91 & 19.24 & 109 & 23.04 & 134 & 28.33 & 112 & 23.68 \\
\hline
\end{tabular}


and energy bars (4.05\%), with fewer than 3\% having sweets and candy (2.93\%), yoghurt $(2.7 \%)$ and fruit juice $(2.93 \%)$. A similar response pattern with both healthy and unhealthy foods was evident at the mid-afternoon snack time. Beverages, especially tea (19.07\%) and coffee $(10.08 \%)$, were enjoyed after supper. It was sometimes accompanied by items such as biscuits or cookies $(9.26 \%)$, rusks $(6.8 \%)$, bread $(5.45 \%)$ as well as chocolates $(6.54 \%)$ and sweets $(5.18 \%)$. A small minority $(4.90 \%)$ had fruit at this time.

The non-quantitative food frequency questionnaire confirmed the assumption that fruit and vegetable consumption was low. With the exception of green vegetables, which nearly a quarter $(24.58 \%)$ of the respondents consumed daily, all other vegetables and fruit were consumed less frequently (Table 4). Many of the respondents indicated that they included fruit and vegetables in their diets three to four times a week. As part of the general food consumption pattern, the frequency of consumption of fast foods, home-cooked meals, readyprepared type of meals, as well as eating out, are illustrated (Table 5). About three-fifths $(58.9 \%)$ of the sample recorded enjoying fast foods once or twice a week, while $17.2 \%$ did so three to four times per week, and $16.2 \%$ never ate these foods. More than $37.7 \%$ of the students consumed ready-prepared, convenience type of meals at least once or twice a week, followed by $26.3 \%$ who had these three to four times per week, while nearly the same percentage $(26.7 \%)$ never made use of this kind of food for meals. This is in striking contrast to home-cooked meals that were enjoyed by $45.4 \%$ at least five to seven times a week; by $20.0 \%$ three to four times; and $21.6 \%$ once or twice a week. Thirteen per cent never consumed such ready-prepared food products. Most respondents (47.7\%) reported that they eat out once twice a month or once a week (35.3\%).

\section{Relationship between BMI, food consumption patterns and lifestyle}

The study also explored the relationship between BMI, gender, food consumption patterns and place of residence. Consideration was given to whether breakfast was eaten or not; snacking between meals; the consumption of fast foods; home-cooked meals; ready-prepared convenience meals; and eating out. Table 5 portrays these results. There were no statistically significant differences between the BMI categories of either males and females regarding the habit of eating breakfast or snacking between meals no matter the time of day, during the mornings, afternoons or after supper. Similarly, when relating BMI categories of the gender groups to the frequency of consumption of ready-prepared convenience take-away fast foods and home-cooked meals, no statistically significant differences were noted. However, a proven ( $p$-value 0.006 ) statistically significant difference was found between BMI categories, gender and frequency of eating out. No statistical difference was noted between BMI 
TAB LE 5 Relationship BMI, gender, food consumption patterns, and residence

\begin{tabular}{|c|c|c|c|c|c|c|c|c|c|c|c|c|c|c|c|c|c|c|c|}
\hline \multirow[b]{3}{*}{ Type of meal } & \multirow[b]{3}{*}{ Consumption pattern } & \multicolumn{8}{|c|}{ BMI categories males } & \multicolumn{8}{|c|}{ BMI categories females } & \multirow{3}{*}{$\begin{array}{l}\text { Total } \\
n\end{array}$} & \multirow[b]{3}{*}{ Sign diff } \\
\hline & & \multicolumn{2}{|c|}{ Underweight } & \multicolumn{2}{|c|}{$\begin{array}{l}\text { Normal } \\
\text { weight }\end{array}$} & \multicolumn{2}{|c|}{ Overweight } & \multicolumn{2}{|c|}{ Obese } & \multicolumn{2}{|c|}{ Underweight } & \multicolumn{2}{|c|}{$\begin{array}{l}\text { Normal } \\
\text { weight }\end{array}$} & \multicolumn{2}{|c|}{ Overweight } & \multicolumn{2}{|c|}{ Obese } & & \\
\hline & & $\bar{n}$ & $\%$ & $\bar{n}$ & $\%$ & $\bar{n}$ & $\%$ & $\bar{n}$ & $\%$ & $\bar{n}$ & $\%$ & $\bar{n}$ & $\%$ & $\bar{n}$ & $\%$ & $\bar{n}$ & $\%$ & & \\
\hline \multirow[t]{2}{*}{ Breakfast } & Yes & 8 & 4.0 & 116 & 57.4 & 65 & 6.4 & 13 & 6.4 & 20 & 10.9 & 152 & 82.6 & 10 & 5.4 & 2 & 1.1 & 398 & 0.528 \\
\hline & No & 1 & 1.6 & 28 & 45.2 & 27 & 43.5 & 6 & 9.7 & 2 & 6.9 & 23 & 79.3 & 3 & 10.3 & 1 & 3.4 & & \\
\hline \multirow[t]{2}{*}{ Morning snacks } & Yes & 6 & 4.0 & 85 & 57.0 & 51 & 34.2 & 7 & 4.7 & 13 & 11.6 & 93 & 82.0 & 4 & 3.6 & 2 & 1.8 & 261 & 0.128 \\
\hline & No & 3 & 2.6 & 59 & 51.3 & 41 & 35.7 & 12 & 10.4 & 8 & 8.0 & 82 & 82.0 & 9 & 9.0 & 1 & 1.0 & & \\
\hline \multirow{2}{*}{$\begin{array}{l}\text { Afternoon } \\
\text { snacks }\end{array}$} & Yes & 4 & 2.3 & 90 & 50.8 & 66 & 37.3 & 17 & 9.6 & 13 & 9.6 & 111 & 81.6 & 9 & 6.6 & 3 & 2.2 & 316 & 0.200 \\
\hline & No & 5 & 5.7 & 54 & 62.1 & 26 & 29.9 & 2 & 2.3 & 8 & 10.5 & 64 & 84.2 & 4 & 5.3 & 0 & 0 & & \\
\hline \multirow[t]{2}{*}{ Evening snacks } & Yes & 6 & 4.7 & 71 & 55.5 & 43 & 33.6 & 8 & 6.3 & 11 & 10.2 & 89 & 82.4 & 7 & 6.5 & 1 & 0.9 & 236 & 0.571 \\
\hline & No & 3 & 2.2 & 73 & 53.7 & 49 & 36.0 & 11 & 8.1 & 10 & 9.6 & 86 & 82.7 & 6 & 5.8 & 2 & 1.9 & & \\
\hline \multirow[t]{4}{*}{ Fast food } & $5-7 \times$ per week & 1 & 4.5 & 11 & 50.0 & 10 & 45.5 & 0 & 0 & 1 & 9.1 & 10 & 90.9 & 0 & 0 & 0 & 0 & 34 & 0.859 \\
\hline & $3-4 \times$ per week & 2 & 3.6 & 27 & 48.2 & 24 & 42.9 & 3 & 5.4 & 1 & 3.7 & 23 & 85.2 & 3 & 11.1 & 0 & 0 & 83 & \\
\hline & $1-2 \times$ per week & 4 & 2.7 & 81 & 55.5 & 47 & 32.2 & 14 & 9.6 & 17 & 13.2 & 105 & 81.4 & 5 & 3.9 & 2 & 1.6 & 284 & \\
\hline & Never & 2 & 5.9 & 21 & 61.8 & 9 & 26.5 & 2 & 5.9 & 3 & 6.7 & 37 & 82.2 & 4 & 8.9 & 1 & 2.2 & 81 & \\
\hline \multirow{4}{*}{$\begin{array}{l}\text { Home-cooked } \\
\text { meals }\end{array}$} & $5-7 \times$ per week & 4 & 3.4 & 73 & 61.9 & 33 & 28.0 & 8 & 6.8 & 14 & 15.1 & 74 & 79.6 & 4 & 4.3 & 1 & 1.1 & 220 & 0.936 \\
\hline & $3-4 \times$ per week & 1 & 2.4 & 19 & 45.2 & 20 & 47.2 & 2 & 4.8 & 4 & 7.7 & 42 & 80.8 & 4 & 7.7 & 2 & 3.8 & 97 & \\
\hline & $1-2 \times$ per week & 4 & 6.7 & 24 & 40.0 & 24 & 40.0 & 8 & 13.3 & 1 & 2.2 & 41 & 91.1 & 3 & 6.7 & 0 & 0 & 105 & \\
\hline & Never & 0 & 0 & 24 & 63.2 & 13 & 34.2 & 1 & 2.6 & 3 & 13.6 & 18 & 81.8 & 1 & 4.5 & 0 & 0 & & \\
\hline $\begin{array}{l}\text { Ready-prepared } \\
/\end{array}$ & $5-7 \times$ per week & 2 & 7.4 & 10 & 37.0 & 12 & 44.4 & 3 & 11.1 & 2 & 11.8 & 15 & 88.2 & 0 & 0 & 0 & 0 & 44 & 0.617 \\
\hline \multirow{3}{*}{$\begin{array}{l}\text { convenience } \\
\text { meals }\end{array}$} & 3-4 × per week & 1 & 1.5 & 36 & 55.4 & 22 & 33.8 & 6 & 9.2 & 8 & 13.6 & 49 & 83.1 & 2 & 3.4 & 0 & 0 & 125 & \\
\hline & $1-2 \times$ per week & 5 & 5.3 & 53 & 55.8 & 31 & 32.6 & 6 & 6.3 & 7 & 8.4 & 68 & 81.9 & 7 & 8.4 & 1 & 1.2 & 179 & \\
\hline & Never & 1 & 1.4 & 41 & 57.7 & 25 & 35.2 & 4 & 5.6 & 5 & 9.4 & 43 & 81.1 & 3 & 5.7 & 2 & 3.8 & 127 & \\
\hline \multirow[t]{5}{*}{ Eating out } & Daily & 0 & 0 & 7 & 58.3 & 4 & 33.3 & 1 & 8.3 & 0 & 0 & 3 & 100 & 0 & 0 & 0 & 0 & 15 & 0.006 \\
\hline & $3-4 \times$ per week & 2 & 8.0 & 16 & 64.0 & 6 & 24.0 & 1 & 4.0 & 2 & 15.4 & 10 & 76.9 & 1 & 7.7 & 0 & 0 & 38 & \\
\hline & Once a week & 1 & 1.2 & 35 & 41.7 & 40 & 47.6 & 8 & 9.5 & 10 & 11.9 & 69 & 82.1 & 5 & 6.0 & 0 & 0 & 171 & \\
\hline & $1-2 \times$ per month & 4 & 3.3 & 76 & 61.8 & 37 & 30.1 & 6 & 4.9 & 9 & 8.4 & 89 & 83.2 & 6 & 5.6 & 3 & 2.8 & 231 & \\
\hline & Never & 2 & 10.0 & 9 & 45.0 & 6 & 30.0 & 3 & 15.0 & 1 & 11.1 & 7 & 77.8 & 1 & 11.1 & 0 & 0 & 29 & \\
\hline Residence & Living with parents & 5 & 6.1 & 41 & 54.7 & 25 & 33.3 & 4 & 5.3 & 5 & 8.9 & 48 & 85.7 & 3 & 5.4 & 0 & 0 & 133 & 0.863 \\
\hline & Live in flat & 1 & 2.4 & 21 & 51.2 & 14 & 34.1 & 5 & 12.2 & 4 & 8.3 & 39 & 81.3 & 3 & 6.3 & 2 & 4.2 & & \\
\hline & House with & 1 & 4.2 & 17 & 70.8 & 4 & 16.7 & 2 & 8.3 & 3 & 11.1 & 21 & 77.8 & 2 & 7.4 & 1 & 3.7 & & \\
\hline & friends & & & & & & & & & & & & & & & & & & \\
\hline & Rent a room & 0 & 0 & 2 & 50.0 & 1 & 25.0 & 1 & 25.0 & 0 & 0 & 1 & 100 & 0 & 0 & 0 & 0 & & \\
\hline & Residence & 2 & 1.7 & 60 & 50.8 & 49 & 41.5 & 7 & 5.9 & 8 & 10.4 & 64 & 83.1 & 5 & 6.5 & 0 & 0 & & \\
\hline
\end{tabular}


categories, gender and place of residence, either living with parents or independently in a flat, an apartment, a house with friends, a room or a university residence.

\section{DISCUSSION}

The prevalence of overweight (21.9\%) and obese (4.5\%) students, classified as those with a BMI greater than $25 \mathrm{~kg} / \mathrm{m}^{2}$, resulted from an analysis of the self-reported weight and height data collected for this investigation. The figures for males were $35.3 \%$ and $7.1 \%$ respectively and $6.0 \%$ and $1.4 \%$ for females. Varying results are reported in other recent South African student studies where weight and height measurements were obtained by trained researchers. In a predominantly white group of students at the University of the Free State, $19.8 \%$ were overweight or obese (Van den Berg et al., 2013), while in a mainly black group of nursing students from the Eastern Cape, 31.7\% and $15.0 \%$ respectively were overweight or obese (Van den Berg et al., 2012). In the comparative study by Peltzer et al. (2014) involving students from 22 low, middle and emerging economies, it is reported that only $55.1 \%$ of the South African female students had a normal BMI, with $25.3 \%$ classified as overweight and $15.6 \%$ as being obese. Among the males, $71.0 \%$ had a normal weight and $13.3 \%$ were overweight and $3.8 \%$ obese. In this present study, the prevalence of being overweight and obese in its entire student group was slightly higher when compared to similar conditions reported in North American and European countries (Cluskey and Grobe, 2009; Chourdakis et al., 2010, Chourdakis et al., 2011) and Australia (Riddell et al., 2011). The South African results raise a concern since overweight and obesity are related to various health risks, such as diabetes, hypertension and hypercholesterolemia (Steyn and Michiza, 2014). Additionally, being overweight at the age of 20-22 years is associated with an increased incidence of obesity by the age of 35-37 years (Chourdakis et al., 2011; Deliens et al., 2013). The differences noted in the overweight and obesity results of the current and recently reported South African studies could possibly be attributed to one or more of the following reasons: race and gender group of the study population; cultural and regional differences in food consumption patterns; and how the weight and height measurements were obtained. The SANHANES-1 study (Shisana et al., 2014: 135), for example reported that black females were significantly heavier and taller than their Asian/Indian and coloured counterparts. Recent food consumption studies confirm that cultural and regional differences continue to exist within the South African population (Labadarios et al., 2011a; Labadarios et al 2011b; Shisana et al., 2014:169). It is further known that self-reported weight and height has limitations, as height is often overestimated and weight underestimated (Shiely et al., 2013; Liechty et al., 2016; Tang et al., 2016) 
The respondents' feelings about their current weight gave interesting insight into their perception of their own weight status. Although the majority were satisfied with their weight, the females felt they needed to lose weight although $84.5 \%$ in the group had a normal weight. The males had a contrasting view of wanting to gain weight although $72.1 \%$ of them had a normal weight. In the study by Gitau et al. (2014) on adolescent boys in Johannesburg, as well as the SANHANES-1 study by Shisana et al. (2014:200), the participating South Africans' perception of their BMls was also measured and compared to their ideal BMI. The same tendency was noted, as South African males, in general, aspired to being heavier and bigger, with females wanting to be thinner. It seems as if the influence of psychosocial factors such as the desirable societal "ideal" body shape (which is often unrealistic) is used by young South Africans as the norm to achieve. A similar finding regarding weight perceptions of male and female Greek students was reported by Chourdakis et al. (2010).

The food composition and meal patterns observed in this investigation confirm Westernorientated food practices as the majority of the respondents consumed three meals a day with in-between meal snacking and had a different meal pattern over weekends. Food intake was characteristically frequent consumption of foods high in fat, sugar and sodium. with a low intake of fruit, vegetables and dairy products. These results concur with other recent studies on South African student groups (Van den Berg et al., 2013; Gresse et al., 2015). Data supported the notion that having a meal at breakfast time was common practice as the majority $(81.3 \%)$ of the present study group consumed typical breakfast items. In comparison to other studies (Hallström et al., 2011; Reeves et al., 2013), it seems as if white South African students are more inclined to eat breakfast. Van den Berg et al. (2013) reported that $93.2 \%$ of their students consume breakfast regularly. Consumption of breakfast is associated with a healthy lifestyle and eating practices, and this truth needs reinforcement. Skipping breakfast is associated with overeating later in the day to satisfy the hunger pangs experienced. Hunger is often calmed down by choosing high fat or sugar-dense snacks (Hallström et al., 2011; Hartmann et al., 2012; Reeves et al., 2013). To note in the present study is that more females have a normal weight and have a regular breakfast than their male counterparts (Table 5). More overweight males in comparison to overweight females did not consume breakfast.

The composition of lunch and snacks between meals reflect that both healthy and unhealthy foods were consumed during the day. This concurs with the food frequency questionnaire results (Table 4 ) as $\geq 23 \%$ of the respondents marked that snack foods that are usually high in fat, sugar or sodium) were indulged in three to four times per week. They were in the form of sweets $(23.13 \%)$, chocolates $(26.1 \%)$, potato chips $(29.18 \%)$, sugar-sweetened beverages $(31.65 \%)$ and fruit juice (39.71\%). Biscuits and cookies were also enjoyed three to four times 
per week by $19.4 \%$ of the students. A further concern is the large majority that do not seem to include fruit and vegetables as part of their regular daily food consumption (Table 4). Nearly $50 \%$ reported that these were consumed only three to four times per week. They thus do not adhere to the South African Food Based Dietary Guidelines which recommend five portions of fruit and vegetables daily (Naudé et al., 2013). These results concur with South African and international studies (Sharma et al., 2009; Chourdakis et al., 2010; El Ansari et al., 2012; Van den Berg et al., 2012; Van den Berg et al., 2013; Peltzer et al., 2014; Gresse et al., 2015). Fruit and vegetables are sources of fibre, vitamins and anti-oxidants that should be part of daily food intake. The frequency of the consumption of dairy products could be improved on as well. Although as many as nearly $60 \%$ (59.66\%) consumed milk daily, nearly $40 \%$ did not.

Lack of time is often seen as a barrier to healthy eating in that people seem to devote less time to meal preparation and eating as a matter of choice when shifting their time allocation schedule or because of a lack of cooking skills, or both of these circumstances (Pelletier and Laska, 2012; De Backer, 2013; Hartmann et al., 2013; Sobal and Hanson, 2014). Advances in food technology have enabled the food industry to also respond by offering time-saving options through the increased availability of convenience and ready-to-eat food (Hartmann et al., 2013). Strategies students and young adults devise to overcome time constraints could incorporate consumption of fast foods, skipping meals or resorting to ready-prepared convenience foods. Although the study group used fast foods regularly, they were not consumed as frequently as reported in other South African and international studies. In the latter case, consumption frequency of three and more times per week were usual (Gresse et al., 2015; Steyn et al., 2011). Home-cooked meals continue to form part of the food consumption patterns of white students as more than $60 \%$ enjoyed such meals three and more times per week. This result could be interpreted as implying that these meals are valued. Since eating out is generally expensive and often regarded as a treat, most students do this either only once a week or once or twice a month. A statistically significant difference was found between the BMI rating and the frequency of eating out. The tendency of a higher body weight to coincide with an increased frequency of eating out concurs with international studies (Van der Horst, et al., 2010; Sobal and Hanson, 2014).

Studies that investigated the association between the BMI and selected consumption patterns yielded positive results in adults concerning the habits of eating breakfast, consuming fast food and snacks and having home-cooked meals (Sobal and Hanson, 2011; Hartmann et al., 2012; Sobal and Hanson, 2014). Student populations (Utter et al., 2013) also reported that BMI was not significantly associated with consumption patterns like these. No statistically significant differences were found between BMI and the type of residence arrangement. 
This study had several limitations. Data was self-reported and, although studies often use selfreported weight and height in population-based studies due to practical, time and cost considerations. The accuracy of the self-reported weight and height can be challenged as the possibility of underestimation of weight and the overestimation of height occurs (Deliens et al., 2013; Liechty et al., 2016; Tang et al., 2016). It is admitted that objective measurement of height and weight using standardised protocols, although time, cost and labour intensive, is the ideal, as it is more reliable and should thus be incorporated in study designs if practically feasible (Liechty et al., 2016; Tang et al., 2016). In the same vein, the self-reported frequency of consumption and patterns of eating practices could be under or over reported in certain cases of the collected food intake data, and consequently suffer from measurement error (Hartmann et al., 2012; Hébert et al., 2014; Subar et al., 2015). However, the present study was explorative in nature. It aimed to describe and gain insight into the type of food a purposively selected student group habitually consumed. Thus the self-reported food intake data aided in characterising and providing an overview of the food choices and food consumption patterns of this group of white students. There is ample evidence that shows that self-reported food intake data can be used successfully to inform dietary guidance to the group studied (Hébert et al., 2014; Subar et al., 2015). Admittedly, only one item was used to measure some variables and concepts. Examples are the frequency of consumption of homecooked meals, fast food and participation in sport or physical activity. More objective measurements of these elements and the habitual food intake, including the quantities and portion sizes of foods consumed, should be considered in future studies. ,

\section{CONCLUSION AND RECOMMENDATIONS}

Despite limitations, this study does contribute to filling the knowledge gap around the paucity of data on the food practices of white South African university students. In this work, food consumption patterns represented situations in which breakfast was either eaten or not; snacking between meals; consuming fast foods, home-cooked meals and ready-prepared, convenience type of meals. No statistically significant differences were found between these food consumption patterns and the students' type of residence or the BMI categories of the male and female students. It is known that certain behaviours are related to a high prevalence of overweight and obesity. Especially important too is the confirmation that this young adult life stage is critical in the shaping of food-related behaviours that will not only affect their own future health, but also that of their future families (Sharma et al., 2010; Schnettler et al., 2015). Thus the low reported intake of fruit, vegetables and dairy products rises significant concerns as the majority of students did not include these items in their daily meal patterns. Of equal 
concern is the fact that nearly a quarter of the students, as frequently as three to four times a week consume snack foods high in fat, sugar and sodium.

Although most of male and female students in the study could be classified in the normal weight BMI group, a striking observation was the prevalence of overweight and obesity among males. Specifically important is the fact that it stood as high as $35.3 \%$ for being overweight and $7.1 \%$ for obesity. These percentages are higher than those reported for males in other recent South African studies on student groups (Van den Berg et al., 2012; Van den Berg et al., 2013; Peltzer et al., 2014). Ethnic representation was not taken into account in the South African study Peltzer and colleagues did in 2014. Indications from other recent work seem to suggest that ethnic background and environmental influences could affect the food environment and food accessibility in such a way as to contribute to a higher incidence of overweight and obesity within some communities and regions of South Africa. Further investigation in this field is required. The study, which Reddy et al. (2008) undertook on South African adolescents, illustrates the feasibility of such research. They found that, amongst white adolescent males, overweight and obesity were higher than was the case among their black and coloured counterparts.

The prevalence of overweight and obesity is increasing in young adults worldwide in conjunction with the incidence of non-communicable diseases as a consequence. It is projected that the intensity and nature of these inflictions will not only rise in South Africa but that more males specifically will be affected. To effectively curb the rising trend of overweight and obesity in the South African population this study indicates that further research regarding the food practices and lifestyle patterns of young South African adults and students is timeous. Apart from quantitative studies to determine how nutritional and socio-economic status, physical activity levels, psychosocial and environmental factors contribute to the obesity pandemic, qualitative studies to gain further in-depth insight and understanding of these aspects should be considered as well. Effective prevention and treatment programs could then be planned through consumer education and facilitation with the emphasis on an increased awareness of healthy weight management and promoting healthy food choices and practices, and increasing physical activity levels. 


\section{REFERENCES}

Abrahams, Z., Mchiza, Z. \& Steyn, N.P. (2011) Diet and mortality rates in Sub-Saharan Africa: Stages in the nutrition transition. BMC Public Health, 11, 801. http:// www.biomedicalcentral.com/1471-2458/11/801.

Audain, K. A. Kassier, S.M. \& Veldman, F. J. (2014) Adolescent food frequency and socioeconomic status in a private urban and peri-urban school in Hilton, KwaZulu-Natal. South African Journal of Clinical Nutrition, 27, 201-207.

Beasley, L.J., Hacklett, A.F. \& Maxwell, S. M. (2004) The dietary and health behaviour of young people aged 18-25 years living independently or in the family home in Liverpool, UK. International Journal of Consumer Studies, 28,335-363.

Brittin, H.C. \& Obeidat, B. A. (2011) Food practices, changes, preferences and acculturation of Arab students in US universities. International Journal of Consumer Studies, 35, 552-559.

Bryant, R. \& Dendes, L. (2008) Fast food perceptions: A pilot study of college students in Spain and the United States, Appetite, 52, 327-330.

Brunt, A. R. \& Rhee, Y. S. (2008) Obesity and lifestyle in US college students related to living arrangements. Appetite, 51, 615-621.

Casini, L., Contini, C., Marone, E. \& Romano, C. (2013) Food habits. Changes among young Italians in the last 10 years. Appetite, 68, 21-29.

Chourdakis, M., Tzellos, T., Papazisis, G., Toulis, K. \& Kouvelas, D. (2010) Eating habits, health attitudes and obesity indices among medical students in northern Greece. Appetite, 55, $722-725$.

Chourdakis, M., Tzellos, T., Pourzitaki, C., Toulis, K., Papazisis, G. \& Kouvelas, D. (2011) Evaluation of dietary habits and assessment of cardiovascular disease risk factors among Greek university students. Appetite, 57, 377-383.

Cluskey, M. \& Grobe, D. (2009) College weight gain and behaviour transitions: male and female differences. Journal of the American Dietetic Association, 109, 325-329.

De Backer, C.J.S. (2013) Family meal traditions. Comparing reported childhood food habits to current food habits among university students. Appetite, 69, 64-70.

Deliens, T., Clarys, P., Van Hecke, L., De Bourdeauduij, I. \& Deforche, B. (2013) Changes in weight and body composition during the first semester at university. A prospective explanatory study. Appetite, 65, 111-116.

El Ansari, W., Stock, C., John, J., Deeny, P., Phillips, C., Snelgrove, S., Adetunji, H., Hu, X., Parke, S., Stoate, M. \& Mabhala, A. (2011) Health promoting behaviours and lifestyle characteristics of students at seven universities in the UK. Central European Journal of Public Health, 19, 4, 197-204. 
El Ansari, W., Stock, C. \& Mikolajczyk, R.T. (2012) Relationship between food consumption and living arrangements among university students in four European countries - A crosssectional study. Nutrition Journal 11, 28, http://www.nutritionj.com/content/11/1/28.

Fisher, H., Erasmus, A.C. \& Viljoen, A.T. (2016) Young adults' consideration of their food choices a propos consequences for their future health. International Journal of Consumer Studies, 40,475-483.

Gitau, T.M., Micklesfield, L.K., Pettifor, J.M. \& Norris, S.A. ( 2014) Eating attitudes, body image satisfaction and self-esteem of South African black and white male adolescents and their perception of female body silhouettes. Journal of Child and Adolescent Mental Health, 26(3), 193-205.

Gordon-Larsen, P., Adair, L.S., Nelson, M.C. \& Popkin, B.M. (2004) Five-year obesity incidence in the transition period between adolescence and adulthood: the National Longitudinal Study of Adolescent Health. American Journal of Clinical Nutrition, 80, 569-575.

Gresse, A., Steenkamp, L. \& Pietersen, J. (2015) Eating, drinking and physical activity in Faculty of Health Sciences students compared to other students at a South African university. South African Journal of Clinical Nutrition, 28, 154-159.

Hallström, L., Vereecken, C.A., Ruiz, J.R., Patterson, E., Gilbert, C.C., Casata, G., Diaz,L. Gomez-Martinez, S., Gross, M.G., Gottrand, F., Heygi, A., Lehoux, C., Mouratidou, T., Wildham, K., Aaström, A., Moreno, L.A. \& Sjöström, M. (2011) Breakfast habits and factors influencing food choices at breakfast in relation to socio-demographic and family factors among European adolescents. The Helena study. Appetite, 56, 649-657.

Hartmann, C., Siegrist, M. \& Van der Horst, K. (2012) Snack frequency: associations with healthy and unhealthy food choices. Public Health Nutrition, 16, 1487-1496.

Hartmann, C., Dohle, S. \& Siegrist, M. (2013) Importance of cooking skills for balanced food studies. Appetite, 65, 125-131.

Hébert, J.R., Hurley, T.G., Steck, S.E., Miller, D.R., Tabung, F.K., Peterson, K.E., Kushi, L.H. \& Frongillo, E.A. (2014) Considering the value of dietary assessment in informing nutrition-related health policy. Advances in Nutrition, 5,447-455.

Igumbor, E. U., Sanders, D., Puoane, T.R., Tsolekile, L., Schwarz, C., Purdy, C., Swart, R., Durao, S. \& Hawkes, C. (2012) "Big food," the consumer food environment, health, and policy response in South Africa. PLOS Medicine, 9, 7, www.plosmedicine.org.

Jensen, M. (2007) Defining lifestyle. Environmental Sciences,4,63-73.

Janse van Rensburg, C. \& Surujlal, J. ( 2013) Gender differences related to health and lifestyle patterns of university students. Health SA, 18,1.

http://dx.doi.org/10.4102/hsag.v18i1.735.

Kelly, N.R., Mazzeo, S.E. \& Bean, M. K., (2013) Systematic review of dietary interventions with college students: Directions for future research and practice. Journal of Nutrition Education and Behavior, 45, 304-312.

Kourlaba, G., Panagiotakos, D.B. Mihas, K., Alevizos, A., Marayiannis, K. \& Tountas, Y. (2009) Dietary patterns in relation to socio-economic and lifestyle characteristics among Greek adolescents: a multivariate analysis. Public Health Nutrition, doi:

10.1017/S1368980008004060. 
Kroone, D. \& Alant, B. (2012) Understanding influences on teenage food choices in a Durban High School with a view of improving praxis. International Journal of Consumer Studies, 36, 472-479.

Labadarios, D. Mchiza, Z. Steyn, N.P., Gericke, G. Maunder, E.M.W., Davids Y.D. \& Parker, W. (2011a) Food security in South Africa: a review of national surveys. Bulletin of the World Health Organization, 89, 891-899.

Labadarios, D. Steyn, N.P. \& Nel, J. (2011b) How diverse is the diet of adult South Africans? Nutrition Journal, 10,(33) http:www.nutritionj.com/content/10/1/33.

Larson, N.I., Harnack, L. \& Nieumark-Sztainer, D. (2011) Assessing dietary intake during the transition to adulthood: a comparison of age-appropriate FFQ for youth/adolescents and adults. Publich Health Nutrition. Doi:10.1017/S136898001100228X.

Larson, N.I., Nelson, M.C., Nieumark-Sztainer, D. Story, M. \& Hannan, P.J. (2009) Making time for meals: meal structure and associations with dietary intake in young adults. Journal of the American Dietetic Association, 109,72-79.

Larson, N.I., Nieumark-Sztainer, D. Story, M., Wall, M.M., Harnack, L. \& Eisenberg, M.E. (2008) Fast food intake: Longitudinal trends during transition to young adulthood and correlates of intake. Journal of Adolescent Health, 43, 79-86.

Laska, M.N., Pasch, K.E., Lust, K., Story, M.\& Ehlinger, E. (2009a) Latent class analysis of lifestyle characteristics and health risk behaviors among college youth. Prevention Science DOI 10.1007/s1121-009-0140-2.

Laska, M.N., Larson, N.I., Neumark-Sztainer, D. \& Story M. (2009b) Dietary patterns and home food availability during emerging adulthood: do they differ by living situation? Public Health Nutrition, 13, 222-228.

Li, K., Concepcion, R. Y., Lee, H., Cardinal, B.J., Ebbeck, V., Woekel, E. \& Readdy, R.T. (2012) An examination of sex differences in realtion to the eating habits and nutrient intakes of university students. Journal of Nutrition Education and Behavior, 44, 246-250.

Liechty, J.M., Bi, X. \& Qu, A. (2016) Feasibility and validity of a statistical adjustment to reduce self-report bias of height and weight in wave 1 of the Add Health Study. BMC Medical Research Methodology, 16,124. Doi:10.1186/s12874-016-0227-y.

Low, S., Chin, M.C. \& Deurenberg-Yap (2009) Review on epidemic obesity, Annals Academy of Medicine, 38, 57-65.

Marquis, M. (2005) Exploring convenience orientation as a food motivation for college students living in residence halls. International Journal of Consumer Studies, 29, 1, 55-63.

Mchiza, Z.J., Steyn, N. P., Hill, J., Kruger, A., Schönfeldt, H.C., Nel, J. \& Wntzel-Viljoen, E. (2015) A review of dietary surveys in the adult South African population from 2000-2015. Nutrients, 7:8227-8250. Doi: 10.3390/nu7095389.

Naudé, C.E. (2013) "Eat plenty of vegetables and fruit every day" : a food-based dietary guideline for South Africa inVorster, H.H., Badham, J.B. \& Venter, C.S. (2013) An 
introduction to the food-based dietary guidelines for South Africa. South African Journal of Clinical Nutrition, 26, S1-S164.

Papadaki, A., Hondros, G., Scott, J.A. \& Kapsokefalou, M. (2007) Eating habits of University students living at, or away from home in Greece. Appetite, 49, 169-176.

Pelletier, J.E. \& Laska, M.N. (2012) Balancing healthy meals and busy lives: Associations between work, school, and family responsibilities and perceived time constraints among adults. Journal of Nutrition Education and Behavior, 44, 481-489.

Peltzer, K., Pengpid, S., Samuels, T.A., Özcan, N.K., Mantilla, C., Rahamefy, O. H., Wong, M. L. \& Gasparishvili, A. (2014) Prevalence of overweight/obesity and its associated factors among University students from 22 countries. International Journal of Environmental Research Public Health, 11, 7425-7441;doi:10.3390/ijerph110707425.

Poinhos, R., Oliveira, B. M.P.M. \& Correia, F. (2013) Eating behaviour patterns and BMI in Portuguese higher education students. Appetite, 71, 314-320.

Popkin, B.M., Adair, L.S. \& Ng, S.W. (2012) Global nutrition transition and the pandemic of obesity in developing countries, Nutrition Reviews, 70, 1, 3-21.

Reddy, S.P., Resnicow, K., James, S., Kambaran, N., Omardien, R. \& Mbewu, A.D. (2008) Underweight, overweight and obesity among South African adolescents: results of the 2002 National Youth Risk Behaviour Survey. Public Health Nutrition, 12, 203-207.

Reeves, S., Halsey, L.G., McMeel, Y. \& Huber, J.W. (2013) Breakfast habits, beliefs and measures of health and wellbeing in a nationally representative UK sample. Appetite, 60, 5157.

Riddell, L.J., Ang, B., Keast, R.S.J. \& Hunter, W. (2011) Impact of living arrangements and nationality on food habits and nutrient intakes in young adults. Appetite, 56, 726-731.

Ronquest-Ross, L., Vink, N. \& Sigge, G.O. (2015) Food consumption changes in South Africa since 2014, South African Journal of Science, 111,9/10,1-12.

Rossouw, H.A., Grant, C.C. \& Viljoen, M. (2012) Overweight and obesity in children and adolescents: The South African problem. South African Journal of Science, 108, 1-7.

Sartorius, B., Veerman, L.J., Manyema, M., Chola, L . \& Hofman, K. (2015) Determinants of obesity and associated population attributability, South Africa: Empirical evidence from a national panel survey, 2008-2012. PLos ONE 10, 6.

E0130218.doi:10.1371/journal.pone.0130218.

Schnettler, B., Miranda, H., Lobos, G., Orellana, L., Sepulveda, J., Denegri, M., Etchebarne, S., Mora, M. \& Grunert, K.G. (2015) Eating habits and subjective well-being. A typology of students in Chilean state universities. Appetite, 89, 203-214.

Scrinis, G. (2015) Big food corporations and the nutritional marketing and regulation of processed foods. Canadian Food Studies, 2, 2, 136-145. DOI: 10.15353/cfs-rcea.v2i2.113.

Sedibe, M.H., Feeley, A.B., Voorend, C., Griffiths, P.L., Doak, C.M. \& Norris, S.A. (2014) Narratives of urban female adolescents in South Africa: dietary and physical activity practices in an obesogenic environment. South African Journal of Clinical Nutrition, 27,3,114-119. 
Sharma, B., Harker, M., Harker, D. \& Reinhard, K. (2009) Living independently and the impact on young adult eating behaviour in Germany. British Food Journal, 111, 436-451.

Sharma, B., Harker, M., Harker, D. \& Reinhard, K. (2010) Youth transition to university in Germany and Australia: an empirical investigation of healthy eating behaviour. Journal of Youth Studies, 13, 353-367. DOI: 10.1080/13676260903447510.

Shiely, F., Hayes, K., Perry, I.J. \& Kelleher, C.C. (2013) Height and weight bias: the influence of time. PLoS ONE 8(1):e54386. Doi:101371/journal.pone.0054386.

Shisana, O., Labadarios, D. , Rhele, T. et al. (2014) South African National Health and Nutrition Examination Survey, 2012 (SANHANES - 1). Cape Town. HSRC Press.

Sobal, J, Bisogni. C.A., Devine, C.M. \& Jastran, M. (2006) A conceptual model of the food choice process over the life course. In Shepherd, R. \& Raats, M (eds) The Psychology of Food Choice. Oxforshire. CABI,

Sobal, J. Hanson, K. (2011) Family meals and body weight in US adults. Public Health Nutrition, doi:10.1017/S136898000127.

Sobal, J. \& Hanson, K. (2014) Family dinner frequency, settings and sources, and body weight in US adults. Appetite, 78C, 81-88.

Steyn, N.P.,Labadarios D. \& Nel, J.H. (2011) Factors which influence the consumption of street foods and fast foods in South Africa a national survey. Nutrition Journal, 10,1-10.

Steyn, N.P. \& Mchiza, Z. (2014) Obesity and the nutrition transition in Sub-Saharan Africa. Annals of the New York Academy of Sciences, 1311, 88-101. doi: 10.1111/nyas.12433.

Stucker, D. \& Nestle, M. (2012) Big food, food systems, and global health, PLoS Medicine, 9, 6, doi:10.1371/journal.p.med.1001242.

Subar, A.F., Freedman, L.S., Tooze, J.A., Kirkpatrick, S.I., Boushey, C., Neuhouser, M.L., Thompson, F.E., Potishman, N., Guenther, P.M., Tarasuk, V., Reedu,J. \& Krebs-Smith, S. M. (2015) Addressing current criticism regarding the value of self-report dietary data. The Journal of Nutrition, 145,2639-45. doi:10.3945/jn.115.219634.

Tang, W., Aggarwal, A.,Moudon, A.V. \& Drenowski, A. (2016) Self-reported and measured weights and heights among adults in Seattle and King county. BMC Obesity, 3,11. DOI 10.1186/s40608-016-0088-2.

Tibazarwa, K., Ntyintyane, L., Sliwa, K., Gerntholtz, T., Carrington, M., Wilkinson, D. \& Stewart, S (2009) A time bomb of cardiovascular risk factors in South Africa: Results from the heart of Soweto study "Heart Awareness Days", International Journal of Cardiology, 132, 233-239.

Utter, J., Denny, S., Robinson, E., Flemming, T., Ameratunga, S. \& Grant, S. ( 2013) Family meals among New Zealand young people: Relationships with eating behaviors and Body Mass Index, Journal of Nutrition Education and Behavior, 45, 3-11.

Vasileska, A. \& Rechkoska, G (2012) Global and regional food consumption patterns and trends, Procedia Social and Behavioral Sciences, 44, 363-369.

Van der Horst K., Brunner, T.A. \& Siegrist, M. (2010) Ready-meal consumption: associations with weight status and cooking skills, Public Health Nutrition, 14, 239-245. 
Van den Berg, V.L., Abera, B.M.M., Nel, M. \& Walsh, C.M. (2013) Nutritional status of undergraduate healthcare students at the University of the Free State. South African Journal of Family Practice, 55, 445-452.

Van den Berg, V.L., Okeyo, A.P., Dannhauser, A. \& Nel, M. (2012) Body weight, eating practices and nutritional knowledge amongst university nursing students, Eastern Cape, South African African Journal of Primary Health Care and Family Medicine, 4, doi:10.4102/phcfm.v4i1.323.

Van Heerden, I.V. \& Schönfeldt, H.C. (2011) The lack of food intake data and the consequences thereof. South African Journal of Clinical Nutrition, 24,10-18.

Van Niekerk, S., Grimmer, K. \& Louw, Q (2014) The prevalence of underweight, overweight and obesity in a multiracial group of urban adolescent schoolchildren in the Cape Metropole area of Cape Town, South African Journal of Clinical Nutrition, 27,18-24.

Van Zyl, M. K., Steyn, N.P. \& Marais, M.L. (2010) Characteristics and factors influencing fast food intake in young adult consumers in Johannesburg, South Africa, South African Journal of Clinical Nutrition, 23, 124-130.

Von Normann, K.( 2009) The impact of lifestyles and food knowledge on the food patterns of German children. International Journal of Consumer Studies, 33,382-391.

WHO. (2015) WHO Global Infobase; Proportional mortality. Accessed November, 17, 2015 at https://apps.who.int/infobase/

Worsley, A., Wang, W.C. \& Hunter, W. (2012) The relationship between eating habits, smoking and alcohol consumption, and body mass index of baby boomers. Appetite, 58, 7480. 